imperfections and sins of man, as well as his potentialities.

When the discussion was thrown open it soon became clear that the motion had found few friends. The first two speakers were classicists; Dr. R. E. Witt spoke from experience as a headmaster of a grammar school and said that the study of Greek seemed to produce a greater humility, a greater readiness to look on the other side of a problem, than the study of seientific subjects. Mrs. M. Lockwood suggested that our leaders should have a humanistic philosophy within which their problems could be judged. Scientific progress seemed frighteningly aimless and uncontrolled; there was a suspicion that the real spur to our scientific effort was simply fear of the U.S.S.R. Prof. Timonen, of the University of Helsinki, pointed out that some of the greatest scientists had had a sound classical education and that this had probably contributed to their elarity of thought and expression.

There followed contributions by four chemists, but only one favoured the motion. Dr. A. C. C. Newman urged the importance of inculcating moral values during the education of the citizen. Political leaders had to deal with issues which were primarily moral and human; so long as they were well advised on scientific questions that was enough. Dr. H. J. Barber suggested that the study of the history of science could provide a valuable synthesis of the humanities and the sciences ; it should take its place in curricula along with political history. Mr. R. A. Frazer disliked the suggestion that the sciences should predominate in education - a balance should be struck with emphasis primarily on the humanities. Mr. F. F. Ross agreed that the learning of Latin was a valuable discipline in primary education, but it should give way to science later. An understanding of man's scientific progress was basic to the study of history.

Prof. Farrington, in replying for the opposition, deplored the fact that the necessary expansion of the science faculties of British universities had been accompanied by drastic reductions in the facilities for studying ancient and modern languages and cultures. This whs bringing about an undesirable change in the character of the universities themselves.

Sir Alexander Fleck, summing up for the motion, strenuously denied that the motives for the expansion of science were political. Man might not live by bread alone, but bread was still a necessity, and it was up to science to provide it. Only if our leaders understood science could it be used to improve life on earth.

Sir Cyril Hinshelwood then put the motion to the meeting and it was heavily defeated. A vote of thanks to the chairman and the speakers, proposed by Dr. S. A. Miller, was carried with acclamation.

N. Lindor

\title{
DETERGENTS, TEXTILES AND DYES
}

\begin{abstract}
A CONFERENCE on "Detergents, Textiles and Colour", organized by the. Textile Institute in collaboration with the Branded Textiles Group, was held on February 11 in the Lesser Free Trade Hall, Manchester. Mr. Roland Thomas (director, C.P.A., Ltd., Branded Textiles Group), opening the meeting, said that the products produced by the Group were guaranteed and that members of the Group were interested in maintaining high quality in a very large range of textile goods. Serious consideration had been given for two and a half years to problems arising from the new detergents; on the subject of deterioration of textiles, the detergent manufacturers' attitude to complaints had been that: (a) they were not true, $(b)$ if true, it did not matter, (c) if it did matter, nothing could be done about it, and $(d)$ if anything could be done, it would be too expensive. The problem was serious, the housewife was lost in the complexities of advertisements and it was the business of industry to find a solution.
\end{abstract}

In the morning three papers were read and a number of excellent demonstrations shown to illustrate loss of tint by lack of fastness of dyes to detergent mixtures, by contamination by fluorescent bleaches and by chemical bleaching.

Mr. C. F. Ward (on behalf of the Branded Textiles Group) referred to the great increase in recent years in the number and variety of textiles and also of detergents and substances added to the synthetic soaps. It was fortunate, he said, that in this change emphasis has been placed by the textile manufacturer more and more upon quality. He listed detergent requirements and mentioned the need for instructions understandable by the non-technical housewife. Detergent compositions were discussed, particularly the so-called optical bleaches-the colourless blue- fluorescing substances used to give the "whiter-thanwhite" look. The danger of transfer of these substances from one article to another in the wash was pointed out and, in particular, the most objectionable effect apon the tint of textiles originally dyed to pastel shades such as peach and nil which, after contamination by the fluorescent optical bleach, appear pink and dirty blue.

Complaints of faults caused by the chemical bleach in the detergent powder, such as 10 per cent sodium perborate, were described; in particular of a royal blue dye on wool which develops yellow patches and spots at temperatures as low as $110^{\circ} \mathrm{F}$. Cellulosic materials develop pin-holes either through the action of particles of the bleach which have not been completely dissolved, or through local traces of metal catalysts causing violent action by the dissolved persalt. Fading of dyes in sunshine while drying on the line may be attributed to incomplete rinsing of alkali. Some optical bleaches are themselves not fast to light and discolour in sunlight. The quite common practice of the housewife adding bleach containing chlorine to a detergent when washing whites leads to further troubles; Mr. Ward said that he understood that organic chloro-compounds are already being added to domestic washing powders in the United States and are being considered for use in Great Britain. He viewed this with the greatest concern, since it would lead to increase of complaints of loss of colour, fading, local bleaching, and loss of wear.

Mr. Ward concluded by saying that the housewife is puzzled by the number of products and the various claims made for them; whereas he had no objection to optical bleaches for those who want them for whites, he did complain that colours of textiles are 
Table 1

\begin{tabular}{|c|c|c|c|}
\hline Soap & $\begin{array}{c}\text { (per } \\
\text { cent) }\end{array}$ & \multicolumn{1}{|c|}{ Non-soap } & $\begin{array}{c}\text { (per } \\
\text { cent) }\end{array}$ \\
\hline Soap & $40-65$ & Sodium alkylanyl sul- & \\
Sodium carbonate & $5-20$ & phonates & $20-22$ \\
Sodium silicate & $3-5$ & other wetting or frothing & \\
Sodium phosphate & $0-10$ & agents & $0-5$ \\
Sodium perborate & $0-10$ & Sodium polyphosphates & $30-40$ \\
& & Sodium perborate & 10 \\
& & Sodium silicate & 5 \\
& & Sodium sulphate & 20 \\
\hline
\end{tabular}

spoilt by them, and argued that there should be available a detergent containing no bleach and no optical brightener.

Mr. F. P. Thompsen (Unilever Ltd.) then spoke on the problem from the point of view of the manufacturer of detergents. He gave the typical compositions of washing powders of the soap (classical carboxylate) and non-soap (synthetic detergents) types, shown in Table 1. Both contain 0-1 per cent of sodium carboxymethyl cellulose and $0.02-0.08$ per cent of optical bleach.

Mr. Thompson claimed that perborates have negligible effects upon most dyes and that oxygenated bleaches do not cause loss of strength of textiles. Perborates give better removal of some soils than manual scrubbing. With reference to the bright blue dye which turns green or yellow, he said that no change in shade is produced by carboxylate soap; with perborate it changes shade gradually, the effect being greater in soaps than in synthetic detergents. The change in colour increases with temperature and with concentration of suds. Loss of strength of textiles is least for the carboxylate soap; but with perborate it is much the same for all types of soaps and detergents.

Mr. Thompson spoke of many reports that no discoloration is caused by repeated washing with optical bleaches. He spoke of the difference between the skills and desires of the housewife and the technical expert, and also of the education of domestic users which is carried on by the makers of detergents.

Mr. G. S. J. White (Imperial Chemical Industries Ltd.) gave a brief account of the outstanding advances in the discovery of new dyes, pointing out that major new discoveries occurred at intervals of about thirty years. The requirements of a dye were listed as, first, ease of application; secondly, colour fastness and, to-day, fastness to detergents; and thirdly, colour gamut. Most attention has been given and most success achieved in making products easier to apply. On the other hand, those dyes most easily applied are least fast, and fastness requires more expensive dyeing processes. A striking demonstra. tion was shown of a blue dye which, when made soluble by sulphonation, is applied easily but shows serious loss of colour on washing. When the dye is chemically bonded by the more expensive process of attachment by the cyanuric chloride reaction, only slight loss of colour occurs. When made soluble by a quaternary nitrogen atom and fixed upon the fabric by dequaternizing, it is fast to detergent; but this is the most difficult and expensive method of dyeing.

Mr. White recalled the pre-war German label guaranteeing fastness of dyed textiles to detergents and light, and mentioned the present 'Felisol' Jabel controlled by an international committe $\Theta$ which tests dyes and dyeings. He regarded the flow of informa. tion from the dye maker to the dye user as very good, but pointed out the paucity of the return of information and complaints from users. He estimated the annual world expenditure on research by dye makers ás $£ 15$ million, of which about $£ 4$ million was spent on the salaries of chemists. He concluded by claiming that the problem of the ultimate consumer who still encounters textile goods of poor washing fastness can broadly find alleviation, if not entire resolution, within the textile industry itself, using the whole wide range of products of the dye manufacturers.

Dr. A. S. C. Lawrence (Sheffield), opening the discussion, said that it was clear that the main reason for the meeting was the composition of detergent mixtures; that the meeting was held to discuss whether the additional obligation laid upon dyestuff makers and textile manufacturers by the composition of detergent mixtures is, first, more than they can be reasonably expected to meet to protect the interests of their users and their own good name; and, secondly, whether this additional obligation is necessary for improving detergents or if it is a passing and unnecessary phase which will die out in a few years.

There were three stages in the development of detergents : first, their appearance on the market and the addition of builders to improve their action upon cotton; they were a boon, especially in hard water. The second step was that of adding a bleach, and the third was the addition of a white substance with blue fluorescence-the optical bleach to give the "whiter-than-white" look. This is a dye and a very bad one because it is not fast to detergents; it is now broadcast throughout the washtub. It might be possible for the dyestuff makers to produce an optical bleach that is fast. Alternatively, following $\mathrm{Mr}$. Ward's suggestion of different products for different duties, Dr. Lawrence suggested three types of detergent; one, consisting of detergent and builder only for use in washing up, for paint, etc., and for all coloured and dark textiles; the second would contain also the bleach for occasional use on whites; and the third would have detergent, bleach and the fluorescent optical bleach for those who wanted it. The makers should sell each in a distinctively coloured packagesay, red, blue or white-upon which their name and instructions should be printed. Members of the public have been so confused by advertisement campaigns that they either fail to read the maker's directions or mistakenly suppose that all brands are equally good.

Dr. Lawrence said that all the intelligent young women whom he had questioned said that they used only carboxylate soap for their clothes and synthetic detergents (often those containing the bleaches) only for domestic housework-a duty for which their formulation makes them unsuitable and uneconomical.

The basic reason for holding the meeting was the policy of marketing detergents which are compounded as Jacks-of-all-trades and masters of none. There seems to be a need for fundamental research into the nature of the soil responsible for the greying of whites and of the forces responsible for its persistent adhesion. The paradox which this material presents is that it is removed by the non-detergent components and not by the soap.

In the discussion, much evidence was given of complaints of faults arising during washing being reported to the manufacturer of the textile article. Patchy changes of shade due to the optical bleaches occur on twin-sets; rhodamine pink is not fast to detergents. The maximum degree of brightness from the optical bleach can be built up in an article free of it by washing in suds, containing none, from other articles which have been loaded. Faults due 
to the perborate chemical bleach include yellowing, said to be due to incomplete rinsing, and loss of colour, both generally and in spots. The latter were attributed to incomplete solution of the perborate in the hot water before the articles to be washed were put in. Two speakers said that they had seen advertisements for detergents on television in which this incorrect and dangerous procedure was shown. It was generally agreed that loss of strength is not a problem and that when it does occur, faulty rinsing is the cause. Bleaching on the line, especially during drying in sunlight, was also attributed to this cause. Serious disquiet was expressed at a report of the addition of bleaches containing chlorine to domestic detergents in the United States, and of their possible use in Britain.

A number of speakers made it clear that they considered that some detergent compositions, likely to cause damage to some textile goods of high quality, are being sold to housewives without adequate and sufficiently clear instructions. It is claimed by the manufacturers of these detergents that their inquiry and education services find none of the faults described. On the other hand, a manufacturer of baby clothes who guarantees to replace faulty goods has reported numerous complaints of change of colour, and said that a recommendation to use a selected detergent free from the objectionable additions has led to a large decrease in the number of complaints. He suggested clear classification of all detergents into two groups, one for whites and one for coloured goods. This and similar labelling proposals were received with applause by the meeting. It was stated that the dyestuff makers were unable to produce an optical bleach fast to detergents.

Dr. A. S. C. Lawrence, summing up, said that three main points had emerged from the meeting. First, that the light-fast dyes, which the dye maker can produce, require dyeing processes to make them fast to detergent compositions as now generally sold and this involves extra cost. Secondly, that the textile manufacturer receives the complaints, for the obvious reason that a woman who has purchased a relatively expensive article will complain to the shop where she bought it rather than write to the manufacturer from whom she has obtained a few pennyworth of detergent. Thirdly, that communication of highly technical matters to and from a technologically ignorant public is impossible, and the claims of success of inquiry and education services of the detergent manufacturers must be regarded with suspicion. New textile goods heavily loaded with optical bleach are already being sold, so that a ban on fluorescent brighteners in detergents would not be enough. It seems that some co-operative standard of labelling by makers of detergents, to distinguish in a simple and unequivocal manner for the ordinary housewife the basic types of composition, is the only satisfactory solution and one much overdue. Alternatively, makers of textiles will have to label their goods, specifying a safe detergent, until the makers of the present potentially harmful compositions, so widely sold, are driven to a more critical consideration of their duty to the public. A. S. C. LAwRENCE

\section{FORESTRY IN THE UNITED KINGDOM}

W HILE the Society of Foresters of Great Britain, having been formed in 1925 , is the youngest of the British societies concerned with forestry, its membership is the most representative of the profession as, although it has an ordinary membership open to all who are interested, it caters primarily for the university graduate and others with equivalent qualifications. Its journal, Forestry, is published twice yearly. During the past year, it has published about a dozen original articles ranging over a very wide field, tending to be ecological rather than technical, though some of them link the two aspects; for example, a study of the effect of rate of growth on the density of timber.

The opening article in the 1958 volume is a thoughtful study by G. B. Ryle (at the time, the Forestry Commission director for Wales) on the social problems and possible developments in upland grazing areas where forestry is the obvious alternative use to sheep farming. A strong case is made for integration of farming and forestry, both uses being taken equally into account; action should be co-ordinated by combined councils and the mistakes of the past should be avoided. There have been faults on both sides, the agriculturist seeing the problem as one of maintaining the farm with the help of subsidies, etc., even when it is uneconomical, or less economical than alternative uses, while the forester has tended to overlook the fact that both winter and summer feed must be available to a sheep farm. Ryle also adduces fairly conclusive evidence that forestry gives more on-the-spot employment than sheep farming- probably twice as much-and stresses the need for improved housing as extensions of existing communities rather than new isolated centres.

A study of the mineral content of standing pine crops on the Culbin Sands by T. W. Wright and G. M. Will shows that a maturing crop with about 50 tons of dry organic substance contains about $170 \mathrm{lb}$. nitrate, $20 \mathrm{lb}$. phosphate, $100 \mathrm{lb}$. potassium, $160 \mathrm{lb}$. calcium and $32 \mathrm{lb}$. magnesium, of which about one-third to one-quarter is in the leaves and so returned to the ground annually; the wood, which alone is ultimately removed (provided the bark is peeled on the spot), contains less than one-fifth of the total. These figures, despite their smallness, are of considerable significance in relation to the very low mineral content of the blown sand.

Two papers deal with different aspects of a field that is attracting increasing attention, namely, the relation between the physical conditions, both natural and due to manipulation, under which trees are grown, and the properties of the timber they produce. Studies of site factors influencing growth are discussed in another two papers dealing, respectively, with wind effects and the measurement of light intensity. Taxonomic studies are represented by a paper on the elms of south Cambridgeshire and one on the named variants of the Scots pine. In view of the importance of the latter tree in afforestation and its wide distribution and range of forms, this analysis of 144 terms already published is a most useful contribution : it describes no less than twentysix geographical varieties and twenty-five habit 